\title{
NONADA OU TRAVESSIA: REFLEXÕES SOBRE O SERTÃO DE GUIMARÃES ROSA E DO BRASIL
}

\section{NONADA OR CROSSING: REFLECTIONS ON THE HINTERLAND OF GUIMARÃES ROSA AND BRAZIL}

\section{NONADA O CRUCE: REFLEXIONES SOBRE EL HINTERLAND DE GUIMARÃES ROSA Y BRASIL}

\author{
Suelen Rosa Pelissaro ${ }^{1}$ \\ Universidade de São Paulo, São Paulo, Brasil
}

\begin{abstract}
Resumo: Trata a relação entre a geografia e a literatura de João Guimarães Rosa. A partir da leitura de seus contos, confrontados com estudos de materialismo histórico que abordam criticamente a territorialização do País, discute-se como a concepção do autor sobre o sertão pode contribuir para um debate geográfico de viés crítico, de maneira a enquadrá-lo entre os pensadores intérpretes do Brasil e seu sentido de formação. Como resultado, compreende-se que sua literatura não só aproximou as duas esferas de conhecimento, como também apresentou as visões de Brasil e de sua constituição dentro dos impasses contextuais de se projetar o país. A contribuição de João Guimarães Rosa para se pensar o sertão como território imbuído de contradições seria um dos grandes legados de todo o conjunto da obra do autor.
\end{abstract}

Palavras-chave: Sertão; Literatura; Território.

Abstract: It concerns the relation between geography and João Guimarães Rosa's literature. From reading his stories, faced with historical materialism studies which approach critically the country's territorialization, it evolves how the author's views about hinterland can contribute to the critical geographical debate, on the way to fit him among the scholars who thought Brazil and its sense of formation. As result, it is understandable that his literature not only approached those two spheres of knowledge, but also presented visions of Brazil and its constitution within the contextual impasses of planning the country. João Guimarães Rosa's contributions to think about hinterland as a territory imbued with contradictions is one of the great legacies of the entire set of the author's work.

Keywords: hinterland; Literature; Territory.

Resumen: Trata la relación entre geografía y literatura por João Guimarães Rosa. De leer sus historias, confrontadas con estudios del materialismo histórico que abordan críticamente la territorialización del país, se discute cómo la concepción del autor del hinterland puede contribuir a un debate geográfico crítico, a fin de enmarcarlo entre los pensadores brasileños y su sentido de formación. A consecuencia, se entiende que su literatura no solo acercó las dos esferas del conocimiento, sino que también presentó las visiones de Brasil y su constitución dentro de los impasses contextuales de proyectar el país. La contribución de João Guimarães Rosa a pensar el hinterland como un territorio

\footnotetext{
${ }^{1}$ Universidade de São Paulo, doutoranda do Programa de Pós-Graduação em Geografia Humana, FFLCHUSP, suelen.pelissaro@usp.br
} 
imbuido de contradicciones sería uno de los grandes legados de todo el conjunto de la obra del autor.

Palabras clave: Hinterland; Literatura; Territorio.

\section{SERTÃO, SERTÕES, UMA QUESTÃO DE OPINIÃES²}

Ao se propor uma leitura geográfica sobre um texto ficcional, depara-se com o desafio de como interpretar determinados conceitos pertinentes à Geografia em textos tidos aparentemente como "não geográficos". Neste texto, destaca-se um termo em especial, sertão, visto que, tanto nas estéticas literárias como na Geografia, ele aparece ao longo do tempo com significados variados.

Faz-se uma relação entre o sertão concebido por Guimarães Rosa e o sertão concebido na Geografia crítica contemporânea a partir do que o primeiro possa contribuir para a compreensão do segundo. De acordo com Adriana Ferreira de Melo (2006), tendo em conta que a Literatura é um conhecimento socioespacial, justamente por não possuir a pretensão de ser um estudo que se preocupa explicitamente com o espaço, ela tem muito a dialogar com a Geografia e, no caso as obras do autor em questão, muito a ensinar aos geógrafos, mais preocupados com o racional, o empírico e o objetivo, esquecendo-se de que a apreensão da realidade é, em si, uma forma subjetiva de vê-la e interpretá-la, pois o real, enquanto produto da representação, tem em si certa parcela de ficção, dado que o conteúdo sensível é filtrado por quem o transmite ao papel ${ }^{3}$.

Cabe, de antemão, apresentar como se compreende o vocabulário geográfico para amalgamar as duas esferas do conhecimento em causa. Aqui, a categoria espaço será entendida tal como Henri Lefebvre a interpreta em A produção do espaço, ou seja, como território, pois, para o filósofo, é a produção do espaço que forma o território. É este fruto das relações de poder entre os homens, que, no mundo moderno, não podem ser entendidas sem a relação objetiva e subjetiva com o sistema produtor de mercadorias e a organização dos espaços apropriados para o capital. Se o sertão se torna espaço

\footnotetext{
2 "Esses gerais são sem tamanho. Enfim, cada um o que quer aprova, o senhor sabe: pão ou pães, é questão de opiniães... O sertão está em toda a parte.” (ROSA, 1986, p. 1, grifo nosso).

${ }^{3}$ A interpretação da obra literária ficcional, apesar de refletir momentos selecionados e transfigurados da realidade empírica, torna-se representativa para algo além dela, principalmente além da realidade prática, o que sugere ao olhar geográfico certo cuidado com tais "verdades", conforme adverte Anatol Rosenfeld (2000, p. 15).
} 
apropriado por uma dinâmica nova e exógena, que nele implanta novas e complexas relações, muitas vezes marcadas por conflitos, então sertão é território.

Dentre as análises recorrentes sobre o sertão, destaca-se o consenso de espaço em sua negatividade, como lócus do atraso. ${ }^{4} \mathrm{O}$ ponto inicial para pensá-lo dentro da Geografia e além dela está no rompimento com as classificações que lhe têm sido atribuídas, geralmente dualistas e arrogantes, devido ao lugar de fala de quem o rotula: sujeito exógeno à sua realidade, que o vê como paisagem exótica a ser suprimida. O sertão que atravessa toda a obra roseana fornece pistas para que a postura autoritária quem o julga, composta por tecnocratas e intelectuais que compõem a intelligentsia, seja superada, pois, em sua "perspectiva rasteira", Guimarães Rosa coloca o sertanejo como homem de primeira categoria, dando a ele a vez de falar, de dentro do sertão, o que ele é.

Apesar de ter alçado voo mundo afora tão cedo, Guimarães Rosa não rompeu laços com o sertão, pois por vezes retornou à terra natal para o encontro com os familiares ali deixados e para dar sentido às lembranças carregadas consigo alhures ${ }^{6}$, oriundas também de sua experiência como médico nos interiores mineiros, de forma a nutrir as raízes que persistiram vivas naquele chão. Assim, ele vai além dos chavões deterministas de atraso e violência, inserindo no debate a problemática do Mal contra o Bem, a prática do "código do sertão" como maneira de sobrevivência - apontado por Maria Sylvia de Carvalho Franco (1997), o qual revela violência e laços de solidariedade entre senhores e homens livres pobres - e, com isso, introduz na discussão um sertão contraditório, presente na nossa formação nacional, ora escapando, ora caindo nas teias das antinomias que conformam a sociedade sertaneja e, quiçá, brasileira.

\section{TRAVESSIAS DO SERTÃO NO ESPAÇO-TEMPO}

A origem da palavra sertão é fonte de polêmica. Ele ocorre como uma variação de mulcetão, derivado do termo bunda michitu ou muchitu, que significa mato, terras distantes da costa, mediterrâneas (GALVÃO, 2003). Também aparece nas formas variáveis celtão ou certão, sinônimo de selva (MOREIRA, 1959), e, ainda, desertão, vindo do latim clássico serere, sertanum (trançado, entrelaçado, embrulhado), desertum

\footnotetext{
${ }^{4}$ Como em Cunha (1905), Palmério (1976), Sampaio (1905) e outros.

${ }^{5}$ Conforme Willi Bolle (2004, p. 76).

${ }^{6}$ Em entrevista concedida a J. Borba em 19 de maio de 1946, no calor da publicação de Sagarana, Guimarães Rosa afirmou: "Comecei a escrever motivado pela saudade do interior de Minas", tornando evidente a possibilidade de rastrear reminiscências em suas obras (LARA, 1996, p. 28).
} 
(desertor, aquele que sai da fileira e da ordem) e desertanum (lugar desconhecido para onde foi o desertor) (AMADO, 1995).

O que se pode afirmar é que geograficamente o sertão está em áreas distantes do litoral, onde o povoamento existe, porém rarefeito. Trabalhando o deserto do Antigo Testamento e a presença desse espaço no imaginário medieval do Ocidente europeu, Jacques Le Goff (1994) conta que ele aparecia desvinculado da ideia de solidão, apesar de distante dos lugares povoados. Concebido como lugar de provações, vida errante e desprendimento, era tido tanto como lugar do maravilhoso, quanto das tentações satânicas. Para ele, sua história "foi sempre feita de realidades materiais e espirituais entrelaçadas, de um vaivém constante entre o geográfico e o simbólico, o imaginário e o econômico, o social e o ideológico" (LE GOFF, 1994, p. 89)7

A adaptação do imaginário construído sobre o deserto bíblico para a concretude espacial em plena Europa medieval do Ocidente se voltava, em linhas gerais, para florestas temperadas, que serviam de fronteira e refúgio para os cultos pagãos, para os eremitas, os vencidos e os marginais - servos fugidos, assassinos, aventureiros e bandidos -, mas também como espaço útil e precioso, esconderijo de riquezas, como caça, mel e metais. Era, como descreve o historiador, "um território suplementar da atividade econômica" (LE GOFF, 1994, p. 90), ao mesmo tempo que espaço de fuga e liberdade. Para lá, corriam os descartáveis daquele contexto, prenhes de novas significações sobre a realidade que viviam, mas jamais absortos dela.

As lendas medievais de riquezas escondidas em áreas distantes ${ }^{8}$ foram fortalecidas e transformadas na Idade Moderna e chegaram ao Novo Mundo a partir do momento em que se iniciou o processo de colonização, tendo os mitos papel importante no movimento, associados à necessidade, seja da fantasia, seja do estômago (MARX, 2013, v. 1). Desde o século XVI, o termo sertão passa a ser utilizado para nomear espaços vastos, interiores, situados dentro das possessões portuguesas recém-conquistadas, sobre as quais os reinóis pouco ou nada sabiam e que, por isso mesmo, eram impelidos a desbravá-los.

\footnotetext{
${ }^{7}$ Outra relação interessante pode ser estabelecida entre o sertão e o wilderness, referente ao oeste norteamericano, também caracterizado pela literatura estadunidense como território ambivalente, onde a natureza é maior que o homem, sendo também lugar de provações e misticismo, em contraposição à visão modernizadora da marcha para o oeste. A literatura em que mais se evidencia tal interpretação encontra-se em Henry Thoreau (2007), Walden, ou a vida nos bosques, e no trabalho de Roderick Frazier Nash (2001), Wilderness and the american mind.

${ }^{8}$ A lenda mais popular no Ocidente medieval seria o mito do país de Cocanha.
} 
Dado o contexto de formação de Estados nacionais e o avanço do sistema de acumulação no Ocidente europeu, o processo de ocupação da América Portuguesa tornase um imperativo da economia metropolitana. O poder reinol estabelece aos poucos as estruturas de comando no território colonial, permitindo a diferenciação entre as áreas ocupadas - localizadas, em sua maioria, na franja litorânea - e as que ainda precisavam ser incorporadas, sendo preciso impor a estas a soberania por meio da penetração em terras densamente florestadas e povoadas por indígenas, em boa parte hostis à submissão. Nesse quadro, foram adicionados ao termo sertão os sentidos "terra desconhecida" e "perigosa", evoluindo a dicotomia para o que está colonizado - o litoral - e o que ainda não foi incorporado pelo colonizador - o sertão (IBGE, 2009).

Com a descoberta de ouro em Minas Gerais, Mato Grosso e Goiás, entre o final do século XVII e o início do XVIII, e as consequentes explosão demográfica, acumulação de fortunas, fundação de núcleos urbanos e implantação da pesada burocracia lusitana, sobretudo na região das minas, os significados negativos atribuídos ao sertão foram reforçados. A concepção do termo irá diferenciar as áreas densamente povoadas e controladas pela Coroa Portuguesa - no caso, as minas - daquelas em que a rarefação de população e o conflito entre diferentes agentes pelo controle do território serão as determinantes para que a ideia de sertão esteja associada à ausência da lei e da ordem ou seja, contraditoriamente, à presença dos currais (IBGE, 2009).

Considerado espaço de refúgio e também de oportunidades, a região que começa a se configurar nos Setecentos como sertão dos currais desenvolve no eixo entre o norte de Minas Gerais e o sul da Bahia uma atividade econômica que não requer grandes investimentos nem exige muitos braços: a criação de gado de corte. Economia dependente da extração de ouro e diamante, a pecuária desenvolve à sua maneira o processo de integração dessa vasta área à totalidade da Colônia, apesar de sua importância menor no ponto de vista do poder lusitano e da persistência de grande desigualdade social ${ }^{9}$.

No século XIX, a partir do processo de independência do Brasil e da necessidade de forjar a nação, discutir o que é o sertão e o que fazer com ele torna-se questão central

\footnotetext{
9 "No agreste, depois nas caatingas e, por fim, nos cerrados, desenvolveu-se uma economia pastoril associada originalmente à produção açucareira como fornecedora de carne, de couros e de bois de serviço. Foi sempre uma economia pobre e dependente. Contando, porém, com a segurança de um crescente mercado interno para sua produção, além da exportação de couro, pôde expandir-se continuamente através de séculos. Acabou incorporando ao pastoreio uma parcela ponderável da população nacional, cobrindo e ocupando áreas territoriais mais extensas que qualquer outra atividade produtiva." (RIBEIRO, 1995, p. 340).
} 
para as camadas dominantes que anseiam o progresso, pensamento que persevera até meados do século XX. Arrefece a produção de metais, enquanto a pecuária dos Gerais se especializa, continuando, à sua maneira, a exercer atividades econômicas na ampla rede que o integra a alhures. A posterior criação da Sudene $^{10}$, que tinha como objetivo introduzir na região Nordeste a modernização de cunho industrial, cujo modelo jazia na região Sudeste, acabou incorporando o norte de Minas Gerais à autarquia. Apesar de criada ainda no fôlego democrático, o órgão só entrou em ação no sertão mineiro durante a ditadura militar, facilitando o acesso às terras cobertas de cerrado via crédito para empresários do setor silvicultor e carvoeiro, tingindo de um verde pálido e homogêneo as chapadas outrora verdejantes. Estradas passaram a interligar os povoados, trazendo novos costumes e produtos, além dos equipamentos que anunciavam a presença do Estado, de capitais e de novas sociabilidades.

Apesar das mudanças, os poderes políticos e econômicos continuavam encarando o sertão como lócus da barbárie e do atraso, vendo nele nada além de precariedade econômica - única vertente analisada e, portanto, insuficiente. De acordo com Antonio Carlos Robert Moraes (2002), os donos do poder permaneciam enxergando o sertão como porção do território nacional em que a atividade econômica não se fazia acompanhar da presença do Estado, lugar longínquo e nascedouro da violência gratuita - o que não são verdades absolutas, pois, se de um lado, a escassez radicalizou a disputa em torno dos meios de vida, de outro, ela favoreceu o estabelecimento dos laços de solidariedade necessários para garantir a distribuição regular dos recursos, como formas de inserção dessas populações à estrutura da sociedade brasileira, em conformidade com Maria Sylvia de Carvalho Franco (1997).

O século XXI não tem apontado para um destino mais feliz. Os sertões continuam alvo de políticas modernizadoras, pois a urgência da exportação de ferro exige grandes volumes de carvão vegetal para as siderúrgicas. É sobre as chapadas que o eucalipto se ergue monótono, a erodir as encostas, cuja areia assoreia as veredas mais embaixo (DAYRELL, 1998). Quando não é a árvore exótica, são os grãos de soja que douram a paisagem progressivamente estéril. Nessas formas racionais de dominação do território, o sertanejo é incluído de forma precária, dadas as transformações das forças produtivas do capital, que gradualmente eliminam a sua substância, o trabalho (KRISIS, 1999).

10 Superintendência para o Desenvolvimento do Nordeste, criada em 1959 no governo de Juscelino Kubistchek. 
Da centralização do Estado $^{11}$ para cá, modernização inclui planejamento. Planejar o território requer assumir que existem regiões marcadas não pela diferença, mas pelas desigualdades, que são, por sua vez, naturalizadas. O sertão, embora povoado na sua particularidade, permaneceu depositário dos estereótipos ligados à carência de modernização. Do ponto de vista das relações capitalistas, o sertão nunca evolui porque ao se repetir o discurso de atraso, ele é contínua e propositalmente desistoricizado.

Salienta-se que o sertão aqui discutido não é o da contemporaneidade, mas aquele que serviu de cenário para os contos selecionados de Guimarães Rosa, que desembocam até pelos idos dos anos 1960. A captura de suas interpretações acerca das metamorfoses espaciais norte-mineiras por meio da ficção busca levar em conta um sujeito que nasceu no sertão, em seguida foi estudar em cidade grande e se tornou funcionário público a representar e defender os interesses de Estado, mas que, sempre que possível, carregou esse lugar de origem consigo. $\mathrm{O}$ autor faleceu quando o país estava prestes a mergulhar no período mais sombrio de sua história recente, só lhe sendo possível captar as mudanças que se passavam no Brasil enquanto as testemunhou. No entanto, sua literatura registra o prenúncio do que esse vasto território viveria nos momentos seguintes, o que torna possível dilatar as análises para o século XXI.

\section{O SERTÃo NA GEOGRAFIA POÉTICA DE GUIMARÃES ROSA}

Para a Literatura, produto social que reflete tempo e espaço determinados, a relação referente às respostas que as formações sociais dão às dinâmicas do capitalismo aparece por meio da ficção, visível no quanto o espaço age sobre o enredo (MORETTI, 2003). Em Atlas do romance europeu (1800-1900), Franco Moretti analisa as características dos romances criados no contexto da consolidação dos Estados europeus e afirma que nos espaços distantes das capitais, em amplas extensões do território, é onde se desenvolvem tramas ficcionais trágico-sublimes, reveladoras de temporalidades diferentes nesse mesmo espaço.

No caso do sertão dos Gerais, a relação com mercados mais abrangentes foi constante, apesar de indireta e não tão profunda quanto nas áreas em que a produção era

\footnotetext{
${ }^{11}$ Entende-se por centralização o momento em que Getúlio Vargas assume o poder em 1930 e desencadeia o processo de autonomização do Estado e as mudanças na política econômica a partir da cisão dos fatores de produção, como terra, trabalho e capital, de forma a melhor posicionar o país na divisão internacional do trabalho.
} 
especializada no mercado externo. Ao se entender o sertão como território apropriado pelo capital, deve-se ter em mente que as relações abstratas nele se instalam e não o dominam apenas materialmente, mas também exercem forte influência na esfera psicossocial de quem o habita, o que significa que nele se encontram todas as contradições inerentes e as resistências possíveis à engenharia do valor. Isso quer dizer que a nova sociabilidade imposta também condiciona a percepção de mundo dos sujeitos, e ao se entrelaçar Geografia e Literatura, torna-se complicado adotar um viés puramente fenomenológico de percepção do sertão, sem considerar a concretude das relações que inspiram a fantasia dos indivíduos, dado que as vivências, sempre relacionais com as pessoas e os espaços delimitados, já contêm sua parcela de alienação e, assim, a transfere para as ficções.

Visto como economicamente pobre, abre-se a possibilidade de pensar o sertão como um território constituído dentro da forma categorial fetichista, que tem respondido às imposições capitalistas à sua maneira, resultando, contraditoriamente, numa realidade complexa, divulgada pelas ficções de Rosa, conforme é apresentado no conto “O burrinho pedrês":

Alta, sobre a cordilheira de cacundas sinuosas, oscilava a mastreação de chifres. E comprimiam-se os flancos dos mestiços de todas as meiasraças plebeias dos campos-gerais, do Urucuia, dos tombadores do Rio Verde, das reservas baianas, das pradarias de Goiás, das estepes do Jequitinhonha, dos pastos soltos do sertão sem fim.

$[\ldots]$

Nos pastos de engorda, ainda havia milhares deles, e até junho duraria o êxodo dos rebanhos de corte. E, como acontecia o mesmo em todas as fazendas de ali próximo, e, com ligeiras variantes, nas muitas outras constelações de fazendas, escantilhadas em torno das estaçõezinhas daquele trecho, era a mobilização anual da fauna mugidora e guampuda, com trens e mais trens correndo, vagões repletos, atochados, consignados a Sítio e Santa Cruz. Depois, nos meados da seca, os pastos se esvaziavam, e os boiadeiros tinham de espalhar-se em direção aos longínquos centros de cria, para comprar e arrebanhar gado magro. Pelas queimadas, já estariam de volta. Repouso. Primeiro sal. Primeiro pasto. Ração de sal todos os meses, na lua nova. E, pronto, recomeçar. (ROSA, 2006b, p. 11, 20-21).

Com as tramas supostamente transcorridas entre os fins do século XIX e meados do século XX, o autor trabalha a jagunçagem, a pobreza econômica, a provisoriedade, $\mathrm{o}$ medo e a desolação do habitante dessas paragens, ilustradas em "A hora e vez de Augusto Matraga", no momento em que seu Joãozinho Bem-Bem decide vingar a morte de um de seus jagunços exercendo a violência sobre a família do assassino: 
- Ai, seu Joãozinho Bem-Bem, então lhe peço, pelo amor da senhora sua mãe, que o teve e lhe deu de mamar, eu lhe peço que dê ordem de matarem só este velho, que não presta pra mais nada... Mas que não mande judiar com os pobrezinhos dos meus filhos e minhas filhas, que estão lá em casa sofrendo, adoecendo de medo, e que não têm culpa nenhuma do que fez o irmão... Pelo sangue de Jesus Cristo e pelas lágrimas da Virgem Maria!... [...]

- Lhe atender não posso, e com o senhor não quero nada, velho. É a regra. Posso até livrar de sebaça, às vezes, mas não posso perdoar isto não... (ROSA, 2006b, p. 384).

No entanto, o autor constrói as tramas violentas junto à beleza da paisagem e do povo sertanejo, seus laços de solidariedade e outras características positivas, tantas vezes enfatizadas no conjunto da obra, como na seguinte reflexão de Riobaldo em Grande sertão: veredas, onde fica claro que o sertão é mais do que apenas a paisagem natural:

Somente que me valessem, indas que só em breves e poucos, na ideia do sentir, uns lembrares e sustâncias. Os que, por exemplo, os seguintes eram: a cantiga de Siruiz, a Bigri minha mãe me ralhando; os buritis dos buritis - assim aos cachos; o existir de Diadorim, a bizarrice daquele pássaro galante: o manuelzinho-da-croa; a imagem de minha Nossa Senhora da Abadia, muito salvadora; os meninos pequenos, nuzinhos como os anjos não são, atrás das mulheres mães deles, que iam apanhar água na praia do Rio de São Francisco, com bilhas na rodilha, na cabeça, sem tempo para grandes tristezas; e a minha Otacília. (ROSA, 1986, p. 457).

Com isso, os textos contemplam o conteúdo poético do território em questão, sem deixar de lembrar um sertão irremediavelmente mergulhado na modernização capitalista, cujas raízes deitam do "sentido da colonização" (PRADO JR., 2006, p. 31) ao programa desenvolvimentista que atravessa de 1930 para cá, guardadas as particularidades contextuais.

Quanto à modernização, Guimarães Rosa deixa claro a perversidade com que ela se aprofunda no território sertanejo, denunciando por meio da ficção um processo que procura homogeneizar aquele rincão encravado no interior do Brasil em nome da produção econômica. $\mathrm{O}$ autor mostra, de maneira implícita, um sistema que atribui poderes mágicos a coisas e anula a existência dos homens enquanto livres, que se tornam esvaziados porque dominados pela mercadoria. Nota-se que a perversidade desse processo reside, especialmente, na tentativa de equalização econômica dos distintos territórios, utilizando como ferramentas para esse fim o poder e a violência 
extraeconômica que procuram destruir as particularidades dos lugares, enfatizando a barbárie inerente às relações capitalistas.

As leituras sobre as ficções roseanas se ancoram em um viés social, seguindo interpretações condizentes com os estudos de Walnice Nogueira Galvão (1986), Antônio José Pasta Júnior (1997), Heloísa Starling (1998), Luís Roncari (2004), Willi Bolle (2004) e muitos outros, inspirados nos trabalhos precursores de Antonio Candido (1970; 2006), que relaciona literatura e sociedade ao longo da formação do Brasil como país independente. O ponto de partida para se pensar a geografia na literatura é ver, a partir da contribuição de Erich Auerbach (2007), como esta é a mimese da relação sociedadeespaço, buscando uma geografia espontânea e solta das amarras institucionais na ficção. Tal confluência revela as sobrevivências mais complexas do sertão roseano, que é produzido de maneira particular, ao mesmo tempo que gradualmente integrado aos países que comandam o sistema produtor de mercadorias.

Partindo-se do pressuposto de que o espaço é criação humana onde se dão as formas de produção da vida e suas sociabilidades, incluindo as modernas, em Guimarães Rosa o sertão se apresenta como um espaço de contradições, tendo em vista as origens de sua ocupação, ou seja, território dominado que integra a formação do capitalismo mundial. Ele aparece em sua fertilidade e esterilidade, beleza e feiura, harmonia e hostilidade, riqueza e miséria, condizente com os moldes dos opostos binários hostis típicos da modernização ${ }^{12}$, como desenvolve Robert Kurz (2010). Porém, o autor também se atentou às diferenças, que, dentro do recorte temporal de toda a sua obra, simplesmente não eram toleradas pelas personificações do $\operatorname{poder}^{13}$, dado que a composição de opostos, típica da moderna relação do valor, abria caminho para a sua aniquilação por meio dos esquemas espacializantes, como o planejamento estatal. Buscando resgatar e valorizar a diferença no modo de viver dos sertanejos, condenada pelos projetos de superação do suposto arcaísmo do sertão, Guimarães Rosa descreve, por exemplo, em carta ao seu

\footnotetext{
12 “Eu vou pr'a o céu, e vou mesmo, por bem ou por mal!... E a minha vez há de chegar... Pr'a o céu eu vou, nem que seja a porrete!..." (ROSA, 2006b, p. 358). A contradição também se faz nos dois momentos em que Riobaldo atravessa o Liso do Sussuarão, em Grande sertão: veredas: na primeira vez, o Liso era deserto e hostil, enquanto na segunda travessia se mostrou fértil e aconchegante.

${ }^{13}$ As diferenças, que também podem ser chamadas de pluralidades, eram entendidas dentro da moderna sociedade do valor como desigualdades e, por isso, deveriam ser aniquiladas pelos processos de homogeneização do capital. Com a transição social para o pós-fordismo, as diferenças passam a ser encaradas pelo neoliberalismo como formas sociais híbridas, fragmentadas e individuais de produção de mais valor, e por isso se tornam valorizadas, a despeito de sua inclusão precária - momento da modernização não alcançado pelo conjunto da obra de Guimarães Rosa. Sobre as diferenças no mundo da mercadoria, ver Scholz (2004).
} 
tradutor para o italiano, Edoardo Bizzarri (2003), o que são as veredas e como se habita nelas e nos chapadões, relacionando as formas de ocupação e de reprodução da vida à excepcionalidade desse território.

Em geral, os moradores dos "gerais" ocupam as veredas, onde podem plantar roça e criar bois. São os veredeiros. Outros, moram mesmo no alto das chapadas, perto das veredinhas ou veredas altas, que, como disse, também há, nas chapadas: estes são os "geralistas" propriamente ditos (com relação aos veredeiros, isto é, em oposição aos veredeiros). Mas o nome de geralista abrange, igualmente, a todos: os veredeiros e os geralistas propriamente ditos. Quem mora nos gerais, seja em vereda ou chapada, é geralista. Eu, por exemplo. Você, agora, também. (BIZZARRI, 2003, p. 40-42, grifos do autor).

Coexistindo entre os sertanejos a violência e a solidariedade, Guimarães Rosa mostra bem esse convívio repleto de contradições, adaptações e diferenças ${ }^{14}$. O modo de vida que o sertanejo desenvolve vem do seu relacionamento íntimo com o meio, já esculpido pela moderna forma social, ao mesmo tempo em que relativamente autonomizada no conteúdo sensível com o mundo em que está subsumido. Isso contribuiu, ao longo de mais de 300 anos, para a construção de uma identidade fortemente enraizada no território e presente na paisagem do sertão, que se mostrava lugar também de esperança, calcada na contradição de ser um expropriado economicamente e submetido à violência das personificações do poder, mas também sensível à cosmologia onde se insere. A identidade sertaneja se traduz, com isso, como contraditória, visto que o sertanejo é moderno, atento ao alto grau de exploração e violência a que está submetido, mas também é sensível às sutilezas das relações e do ambiente em que é forjado. Sertão e sertanejo, criações das fímbrias da expansão e dominação do sistema produtor de mercadorias, sobrevivem reagindo às suas constantes condenações, fortes que existem por causa do mundo do valor e apesar dele. Quando Guimarães Rosa prenuncia a vida errante de sertanejos fadados a abandonar a terra onde se constituíram, parece estar indagando o que está sendo brutamente rompido com o moderno. Se mais uma vez a expropriação acontece às custas do desenvolvimento, desta vez ele está acompanhado do

\footnotetext{
${ }^{14}$ Um exemplo para se pensar a coexistência entre a contradição e a diferença está nos camponeses, nomeados pelo autor de "capiaus". O camponês que vem a se constituir no Brasil, encarado ahistoricamente como refratário ao capitalismo, tem sua origem na expropriação que o desenrolar do próprio sistema produziu. Ao ser produto da moderna relação, ele contradiz a totalização de uma lógica que expulsa e espolia os sujeitos mais vulneráveis, que são jogados para as fronteiras abertas, onde vivem de forma "diferente", resultado e resistência à homogeneização, que, na modernização sempre reposta, não tarda a inclui-los de forma precária. Sobre esse assunto, ver Martins (2004).
} 
planejamento. Sendo este racional, ele tende a erodir a capacidade inventiva e imaginária dos sujeitos.

Partilhando do mesmo ponto de vista de alguns teóricos que se debruçam sobre a obra roseana - como Bolle, Roncari, Wisnik, entre outros -, é possível afirmar que o escritor produziu uma "história literária" (RONCARI, 2002, p. 246-247) junto a uma "geografia poética" (BIZZARRI, 2003, p. 136) sobre o sertão dos Gerais e, quiçá, sobre o Brasil, dissimulando a história para melhor desvendá-la (GALVÃO, 1986). Trata-se de uma leitura geográfica da obra roseana, que busca romper com os estereótipos sobre o sertão, visto que o apresentado pelo autor é outro, no qual as veredas são riachos que cortam os campos gerais, com vegetação composta pelo cerrado e pelas matas ciliares. Mas a atenção se volta mais a captar como Guimarães Rosa percebe a modernização no dia a dia sertanejo, que dos tempos remotos até o desenvolvimentismo oprime seus habitantes pela espoliação da terra e da riqueza gerada, pela submissão nas relações sociais e pela negação do acesso às veredas e chapadas a esses homens "provisórios" (ROSA, 1986, p. 364), que são mobilizados rumo à cidade grande conforme são descartados dos processos da modernização produtiva promissoras de um progresso ilusório.

A seleção de dois de seus livros para esta análise, Sagarana (2006b) e Primeiras estórias (2006a), se dá porque no primeiro, lançado em 1946, é possível identificar contos que se passam antes da Revolução de 1930, e os consequentes embates e enlaces entre a centralização do poder e o coronelismo. Neles, flagra-se um sertão onde os pastos das chapadas carecem de fecho, povoado esparsamente por pobres vilarejos, arraiais e fazendas de gado em veredas, cheios de recados entre bandos de jagunços que, pausmandados, impõem as regras aos capiaus por meio da violência. Um sertão que é natureza, mas, sendo território, é também espaço produzido, que guarda o sensível do povo, num convívio entre a herança material da exploração colonial - as rugosidades das fazendas em ruína, com suas senzalas abandonadas, tal como aparece em "Sarapalha" - e o legado imaterial e metafísico contido na experiência antropológica não apenas do negro - como em "Corpo fechado", "São Marcos" e "A hora e vez de Augusto Matraga" -, como também do homem livre pobre.

No segundo, publicado em 1962, o sertão roseano se torna alvo de novos projetos com velhas ambições econômicas, como mostra o conto "As margens da alegria", que abre o livro: 
A grande cidade apenas começava a fazer-se, num semi-ermo, no chapadão: a mágica monotonia, os diluídos ares. [...]

Mal podia com o que agora lhe mostravam, na circuntristeza: o um horizonte, homens no trabalho de terraplenagem, os caminhões de cascalho, as vagas árvores, um ribeirão de águas cinzentas, o velamedo-campo apenas uma planta desbotada, o encantamento morto e sem pássaros, o ar cheio de poeira. Sua fadiga, de impedida emoção, formava um medo secreto: descobria o possível de outras adversidades, no mundo maquinal, no hostil espaço; e que entre o contentamento e a desilusão, na balança infidelíssima, quase nada medeia. (ROSA, 2006a, p. 50, 52).

Ele descreve a construção "derrubadora" do cerrado para abrigar a grande cidade anônima. Não por coincidência, o livro encerra os 21 contos com "Os cimos", uma espécie de continuação do primeiro conto, em que o cenário e os personagens são os mesmos, apesar de o Menino já não ser, por dentro, o mesmo que aparece no texto inicial.

Dadas as condições preexistentes de cada parte do território, como os recursos materiais, as formas de organização e as condições de diferenciação de cada região, cada uma dessas partes acaba por responder, à sua própria maneira, às imposições do capitalismo, absorvendo-as à sua maneira - e pagando, por isso, alto preço. Dado o ocaso da economia mineradora, nos enredos de Sagarana e Primeiras estórias, o sertão dos Gerais chega economicamente decadente à Primeira República ${ }^{15}$, mas seguindo integrado à unidade nacional, visto que os “coronéis", grandes latifundiários, eram a base política dos governadores, sobre os quais se assentava o poder do Estado. Num país fortemente agrário, como era o Brasil naquele período, os líderes dos partidos tinham que estabelecer um acordo com os donos da terra, pois, na verdade, eram eles os chefes políticos locais (SADER; PAULINO, 1996). Naquele momento, o Estado era visto e utilizado como "propriedade" do grupo social que o controlava, sendo legitimado e bem-vindo apenas quando os grupos dominantes recorriam a ele para solucionar seus problemas, porém, quando aparecia autônomo, sua interferência nas transações era indesejada.

Do ponto de vista histórico e político, a presença enviesada do Estado como estímulo às relações mercantis e sua utilidade pelos grupos dominantes marcavam profundamente, por sua vez, o seu desencontro com o homem livre pobre, pois, de acordo com Maria Sylvia de Carvalho Franco, as dimensões fundamentais da sociedade

\footnotetext{
${ }^{15}$ A decadência da mineração de ouro e diamantes, além do fim do escravismo, ofusca a economia pecuária do sertão, que abastecia esses centros de exploração mineral. Porém, a região pecuária como um todo permanece na mesma função produtiva, só vindo a receber os ímpetos modernizadores a partir da engrenagem política desenvolvimentista.
} 
estiveram muito mais fortemente encobertas para o homem comum do que o estariam caso apenas a ambição as velasse (FRANCO, 1997). A ordem do Estado e a presença da Justiça, quando apareciam pelos Gerais, muitas vezes eram estranhas ao sertanejo, que nem por isso deixava de recorrer a ambos, em claro sinal de mudança de tempos: se em "A hora e vez de Augusto Matraga", que conclui Sagarana, a justiça é feita com as próprias mãos, nos contos de Primeiras estórias existe a busca por um intermediário de conflitos ou uma mudança de comportamento. Guimarães Rosa encena isso várias vezes nesse livro, como no enredo de "Fatalidade", que trata da peleja de um capiau que decide recorrer à Justiça para se livrar de um valentão que desaforava a sua mulher; ou mesmo em “Os irmãos Dagobé”, quando esperava-se no povoado a chuva de balas após um capiau matar um jagunço: "Tempos, estes. E era que, no lugar, ali nem havia autoridade" (ROSA, 2006a, p. 73, grifos nossos). E ainda em "Famigerado", tratando do acanhamento de um jagunço frente a um técnico letrado do governo.

A manutenção das regras de convívio que garantiam as posses dos coronéis era praticada pela valentia do jagunço, oriundo de um passado de insegurança e desobrigação do trabalho, mas preso pelo poder do latifundiário, como exemplifica esta passagem de "A hora e vez de augusto Matraga":

Dali a pouco, porém, tornava o Quim, com nova desolação: os batepaus não vinham... Não queriam ficar mais com Nhô Augusto... O Major Consilva tinha ajustado, um e mais um, os quatro, para seus capangas, pagando bem. Não vinham, mesmo. O mais merecido, o cabeça, até mandara dizer, faltando ao respeito: - Fala com Nhô Augusto que sol de cima é dinheiro! ...Pr'a ele pagar o que está nos devendo... E é mandar por portador calado, que nós não podemos escutar prosa de outro, que seu Major disse que não quer. (ROSA, 2006b, p. 350).

Guerreando para manter a ordem em nome de outrem, ele usa a violência, sem muitas vezes saber que assim perpetua sua condição de miserável e de homem provisório, alienado num mundo onde a mercadoria impera. Ele põe em ação a regra da vingança, a qual vige num claro conflito de inimizades e alianças num mundo onde não vigora a lei, cumprindo determinações emanadas do poder central, para manter acima de tudo os interesses particulares de poucos (WISNIK, 1998). Diferentemente do que se costuma pensar, o jagunço faz parte de um sistema moderno, pois seu trabalho se resume apenas à imposição da violência particular para manter a ordem da região produtora, papel que segue cumprindo nos Novecentos. 
$\mathrm{O}$ sertão dos Gerais ingressa no século XX pertencente à rede que o articula aos espaços mais valorizados pelo sistema capitalista desde a colonização, onde as imposições do capital condicionam crises do trabalho, fragmentação da dimensão espacial e do homem e a provisoriedade e mobilidade que tanto marcam o sertanejo. Porém, ao ser concebido de cima para baixo como ideologia geográfica, ele é lido como excluído de todos os liames econômicos, políticos e sociais, cabendo à tecnocracia vigente programar a reposição da territorialização sob os novos ditames da onda modernizadora. Todo esse complexo social se desdobra na ficção, dado que o sofrimento que o processo impõe cai sobre essa gente que vive nele, até então desumanizada pelos interesses em disputa entre os atores hegemônicos.

Erich Auerbach (2007) já atentava para certas características do romance moderno, em íntima relação com as transformações sociais, dando ênfase em homens anônimos e seu dia a dia, a fragmentação espacial que adentra o ser, tornando tudo fluido e inconstante, convertendo-o em um "anti-herói”, num mundo que se transforma violentamente, graças, sobretudo, à ciência, à tecnologia e à economia, que se reproduzem dispensando a ética e o acesso livre ao conhecimento. Como as mudanças não ocorrem uniformemente em toda parte, há estranhamento, esfacelamento e perturbando os homens, que vagam sem sentido, buscando o mínimo de sobrevida.

Em "Duelo" (2006b), conto em que por causa de mulher Turíbio Todo persegue seu inimigo e, ao mesmo tempo, foge dele, dois fragmentos exemplificam consequências da crise do trabalho oriundas do colapso da modernização no país: o primeiro trata da "vadiagem" do personagem, porque sua profissão de seleiro perde importância para a construção da estrada de ferro e para a inserção do automóvel:

Não tinha, porém, confiança nesses dotes, e daí ser bastante misantropo, e dali ter querido ser seleiro, para poder trabalhar em casa e ser menos visto. Ora, com a estrada-de-ferro, e, mais tarde, o advento das duas estradas de automóvel, rareavam as encomendas de arreios e cangalhas, e Turíbio Todo caiu por força na vadiação. (ROSA, 2006b, p. 153).

O segundo trata do encontro no meio do caminho com baianos que migravam para São Paulo em busca de trabalho nas fazendas de café: "Depois, uma turma de sujeitos alegres o interpelou. Iam para o sul, para as lavouras de café. Baianos são-pauleiros [...]" (ROSA, 2006b, p. 173).

Primeiras estórias retrata um momento importante para o Brasil. O país mergulhava na breve e conturbada experiência democrática, conhecendo o avanço da 
industrialização e da tecnologia, o desenvolvimento explosivo das cidades, a revolução da mídia, a normatização do trabalho, a expansão dos mercados, e a exacerbação do imperialismo em duas guerras mundiais, a emergência das massas no cenário político e o despertar de uma consciência do "Terceiro Mundo" - que levou a uma revisão radical das relações entre o habitante dos centros do poder e "o outro", antigamente longínquo e “exótico" (BOLLE, 2004, p. 34). É nesse momento que a razão dualista, divulgada por Jacques Lambert (1972) como uma leitura de Brasil dividido em dois, sendo um litoral urbano, civilizado e moderno, em contraposição a um interior (ou vasto sertão) atrasado, pobre e bárbaro, aparece motivadora de planejamentos regionais, culpando as distintas regiões pelo atraso e pelas "disparidades", devendo ser todas "ajustadas" para a otimização da produtividade nacional ${ }^{16}$.

A construção da cidade $^{17}$ que derruba o cerrado, como aparece no conto "As margens da alegria” (2006a), devasta também os lugares presentes no dia a dia ficcional e transforma a identidade do sertanejo, que, deslocado e posto a nu diante da fragmentação do território e de sua vida, se sente perdido e impelido a sair dali. Não é por acaso que o conto "O espelho" (2006a), que trata das reflexões de um sertanejo urbanizado, encontra-se no meio do livro, projetando nos outros contos a melancólica sensação de perda de referenciais em meio à barbárie anônima da destruição dos lugares, porque o progresso e a lógica da mercadoria se tornam mais importantes do que a vida. Esse processo, que separa significante de significado, sujeito de objeto, aprofunda a crise no mundo moderno, com indivíduos que cada vez mais perdem seu sentido.

O sertão é destruído para ser transformado em cidade artificial e símbolo vertical do poder instituído do Estado capturado pelo valor, que cada vez mais perde força e se ancora na racionalidade do mundo da mercadoria que, dominando todas as esferas da vida, se impõe como uma totalidade totalitária e fatal. A essa tarefa se unem em pacto os interesses dos latifundiários rurais e os da burguesia urbana industrial, repetindo a história das alianças de interesses desde os Quinhentos (BOLLE, 2004; OLIVEIRA, 1977). No

\footnotetext{
${ }^{16}$ É interessante notar que o filme Cabra marcado para morrer (1984), de Eduardo Coutinho, cujas gravações começaram a ser feitas em 1962-1964 pelo Centro Popular de Cultura (CPC) da União Nacional dos Estudantes (UNE), grupo jovem carregado de ideias preconcebidas e dualistas, apresenta, após dezessete anos de gravações interrompidas pelo regime militar, a surpresa de descobrir no sertanejo a capacidade de organização social e de ir contra a realidade opressora da qual faz parte, refutando a divisão do país entre litoral moderno e rico e sertão atrasado e pobre, revelando nas telas o universo do outro, que nada mais é do que parte da história e da realidade do país por inteiro.

${ }^{17}$ Em "Entrevista com João Guimarães Rosa", concedida a Fernando Camacho para a Revista Humboldt, o escritor confirmou ser a cidade de Brasília a sua inspiração para os dois contos de Primeiras estórias, "As margens da alegria" e "Os cimos" (PACHECO, 2006).
} 
projeto modernizador, vigora a promessa de aniquilar a violência - que em grande parte é oriunda do sofrimento imposto pelo capital -, valendo-se dela própria para isso. Nessa tela, desenha-se a imagem de uma sociedade expropriada que se criminaliza na medida em que avança mais um passo na modernização, recolocando, aberta até hoje, a questão formulada ainda no início da República brasileira: “Onde está o centro e onde está a periferia da barbárie?” (STARLING, 1998, p. 172).

A contradição do sertão roseano e dos sertanejos que o constroem deixa motes para se pensar os caminhos que o Brasil e seu corpo de intelectuais tomam ao debutar no século XXI. Refletindo sobre o problema do lugar, entendido a partir de Henri Lefebvre (2006) como parte do espaço onde se constrói cotidianamente a vida, crê-se que, com a devastadora modernização retardatária ${ }^{18}$ que abrange os Gerais e as imposições e o autoritarismo que marcam o atual contexto da globalização, os lugares desapareçam e, consigo, a memória do vivido, que fenece na fragmentação dos homens vitimizados pelo progresso, que vão se deslocando dali. Guimarães Rosa dá a pista para a resistência dos lugares e da história do povo, por meio da memória narrativa, que tende a migrar com o sertanejo para as cidades - até porque o próprio escritor foi um sertanejo que correu o mundo escrevendo sobre sua terra natal, pelo que viveu e também pelo que colheu das lembranças alheias. Não seria por acaso que o seu "discurso labiríntico", como Bolle (2004, p. 84) o classifica, seja uma costura de lembranças dos lugares e de sua gente, no qual a fragmentação do texto reflete a fragmentação da memória e da sensação de pertencimento ao lugar.

O sertanejo carrega a tiracolo o seu sertão memorável, bom e mau, para espaços distantes onde ele, o outro, se mistura à massa de gente que igualmente é preterida na gigante economia moderna, lutando contra a morte e tentando se reproduzir socialmente. Os homens pagam pela modernização o preço da indiferença do mercado pela origem das pessoas que nele vêm trocar mercadorias, deixando que suas possibilidades inatas sejam modeladas pela produção das coisas que se podem comprar, o que os torna iguais, como lembram Theodor Adorno e Max Horkheimer (1985).

18 Conceito tomado de Robert Kurz (1992, p. 35, 166-167), que alude ao impulso forçado de desenvolvimento econômico nas regiões ainda pouco desenvolvidas - ou seja, os países do hemisfério Sul -, no qual o elemento estatista se impõe frente ao monetarista para possibilitar processos de industrialização e modernização. No desenrolar desse projeto, mantêm-se os grupos parasitários no comando, ao mesmo tempo em que a grande massa da população fica de fora da produção para o mercado mundial, perpetuando a miséria. 
No entanto, o sertão dos Gerais também é lugar de resistência às severas imposições da produtividade, pois abriga pessoas que portam um modo de ser muitas vezes à revelia dos padrões impostos, o que quer dizer que interpretá-lo a partir de um viés puramente economicista é incorrer num olhar superficial sobre ele. Há o consenso de que no sertão predomina o ritmo dado pela natureza (MORAES, 2002), porém, a diferença é que a relação do sertanejo com o lugar onde vive não é só de repulsa e hostilidade, mas também de harmonia. Guimarães Rosa, ao não partilhar da visão dualista (SPERBER, 1996) e olhar o sertão a partir de dentro, revela claramente em suas obras a beleza de um território que se torna lugar para quem o habita, posto que é construído a partir de memórias. Rende-se aqui à categoria lugar, sinônimo de uma porção do espaço apropriável para a (sobre)vida, por meio do corpo e dos sentidos. Os lugares são partes do espaço onde os sujeitos reconhecem sua história, suas experiências, seus conflitos e sobrevivências, despertando sensações de identificação e projetando ações no dia a dia.

Em Guimarães Rosa, o sertão é uma fortuna de lugares, e em todos eles jaz a contradição inerente ao mundo moderno em que ele foi talhado:

- "Mano velho, tu é nado aqui, ou de donde? Acha mesmo assim que o sertão é bom?..."

Bestiaga que ele me respondeu, e respondeu bem; e digo ao senhor:

-"Sertão não é malino nem caridoso, mano oh mano!: - ... ele tira ou dá, ou agrada ou amarga, ao senhor, conforme o senhor mesmo". (ROSA, 1986, p. 460).

Apesar de o sertanejo estar preso a um modo de vida miserável - em que a regra é a lei e só tem vez aquele que tem posses, em que o homem livre pobre é vulnerável à violência, tanto como vítima quanto como agente, já que o demônio do dinheiro marca cruelmente os destinos das pessoas, alimentando a luta de morte em vidas que, despedaçadas, perdem seu sentido -, os textos roseanos contemplam "a emergência da pura graça em condições hostis e carentes" (WISNIK, 1998, p. 190), aparecendo personagens que são as vítimas descartáveis no mundo em crise, como loucos, crianças, velhos etc., exatamente os maiores prejudicados pelas convulsões econômicas. Primeiras estórias traz esses exemplos: em "Partida do audaz navegante", num mundo rural distante, esquecido e embrutecido, a "trampa seca de vaca" se transforma, pela imaginação das crianças, no navegante apaixonado que vai partir do mundo de margaridinhas, josés-moleques e douradinhas para "Ir descobrir outros lugares, [...] porque os outros lugares ainda são mais bonitos” (ROSA, 2006a, p. 159). Que dizer do 
enredo de "Substância", em que acontece o "não-fato, o não-tempo, silêncio em sua imaginação" (ROSA, 2006a, p. 190), quando o amor acontece em meio à dura lida da roça, no sofrimento do fabrico do polvilho, consagrando uma mulher condenada pelo destino?

A própria característica de anticlímax em muitos dos contos também exemplifica a situação: quando o esperado sempre é a via da violência ou a aceitação de uma sina infeliz imposta como fardo, os desfechos surpreendem o leitor, impelido a refletir e a compreender o outro, o sertanejo, que é, senão, a sua própria extensão. Esse jogo, em que tudo é possível, permite rever preconceitos e dicotomias e tratar esse sujeito não como portador de violência gratuita nem como pobre criatura determinada pelo meio depauperado em que vive, mas como sobrevivente de um espaço em que Bem e Mal se misturam, em que a dimensão ética pesa sobre as ações, revelando a sua face mais humana. Preso à forma moderna, é dentro dela que a busca por sobrevivência nem sempre deságua na brutalidade, pois a sociabilidade exigida pelo mundo do valor também incorre, paradoxalmente, em solidariedade necessária.

Adotar a leitura do sertanejo como não civilizado é incorrer também no dualismo Brasil moderno versus Brasil atrasado. Ela o rotula como homem violento e bárbaro, que não se adapta à cidade, tida como lado oposto do sertão, esquecendo-se de que, sendo este mundo misturado, o sertanejo também o é e traz consigo propriedades sensíveis e a possibilidade de desvio do sofrimento da realidade por meio da doçura que as frestas da vida também podem oferecer, buscando noutros espaços a possibilidade de o lugar existir. Justamente onde há repressão e constrangimento é que existem as possibilidades do novo.

Alguns contos de Primeiras estórias sinalizam essa travessia do sertão rumo à cidade, e do sertão brotando de dentro da cidade: a cena de Soroco, que aguarda o trem que parte para Barbacena; a partida de todos para longe, excetuando o narradorpersonagem, em "A terceira margem do rio"; o discurso da "Benfazeja", solenemente dirigido aos cidadãos; os irmãos Dagobé, que deixam a vida jagunça em busca de outras possibilidades de vida na cidade, mostrando que o sertão é, também, dentro da gente, e ele é a bagagem íntima carregada por todo sujeito que dele sai.

Olhou-o curtamente. Levou a mão ao cinturão? Não. A gente, era que assim previa, a falsa noção do gesto. Só disse, subitamente ouviu-se: "Moço, o senhor vá, se recolha. Sucede que o meu saudoso Irmão é que era um diabo de danado..."

Disse isso, baixo e mau-som. Mas se virou para os presentes. Seus dois outros manos, também. A todos, agradeciam. Se não é que não sorriam, 
apressurados. Sacudiam dos pés a lama, limpavam as caras do respingado. Doricão, já fugaz, disse, completou: - "A gente, vamos 'embora, morar em cidade grande..." O enterro estava acabado. E outra chuva começava. (ROSA, 2006a, p. 75, grifos do autor).

Nas metrópoles, encontra-se o maior número de pobres, limitados à circulação dentro da grande cidade porque sobrevivem segregados em fragmentos. Porém, são nesses fragmentos que os laços de sociabilidade das pessoas se fortalecem, resistindo e superando, cotidianamente, o imperialismo severo do capital e dos objetos técnicos. Milton Santos (2000) aposta na capacidade do lugar e do homem livre pobre de hoje (liberdade duvidosa) em subsistir às padronizações econômicas, fazendo suas manifestações, escrevendo a sua história e construindo o seu lugar no dia a dia. Nessa tarefa, não vale o uso da violência como única ação transformadora do devir, mas o uso do Bem, da ética que há muito acompanha o sertanejo migrante, para vencer o Mal que impregna os espaços da cidade e que vem de todos os lados, na construção de um mundo possível, no qual o Bem finalmente persevere - objetivo cada vez mais distante de ser alcançado: quanto mais os países de passado colonial se especializam na produção de riquezas supérfluas voltadas para a exportação, mais se tornam vulneráveis a crises, o que aumenta a pobreza interna e cria forte tensão, que explode em violência incontrolável (KURZ, 1992). Enquanto faz-se urgente propor alternativas concretas ao mundo em crise, a ficção roseana mostra que do mesmo berço do Mal pode sair o Bem: está também no sertanejo migrante a possibilidade de oferecer o anticlímax à racionalização crua e brutal do mundo. A literatura de Guimarães Rosa pode ser lida sob esta chave de interpretação também.

Nos contos roseanos, a realidade, a prática do sertanejo que procura sobreviver às forças opressoras em qualquer lugar que esteja, já está posta diante dos olhos do leitor. Ao propor Guimarães Rosa como um intérprete do Brasil, não se pode negligenciar a sua atuação como técnico do Estado. Sua situação ambígua de vir do sertão e de integrar os doutores a serviço do governo induz a pensar sobre como o autor transitou entre ambos os polos - talvez por isso sua narrativa tenha encontrado na ficção a liberdade em apresentar as incongruências de um país, negadas pelos relatórios burocráticos. É importante considerar o escritor para além da sua vaidade em transformar a literatura regionalista, pois foi um sujeito letrado, desde jovem mobilizado para o trabalho complexo, que ora representou o país na Hamburgo sob Hitler ou na demarcação de fronteiras em Itaipu, ora retornou à terra natal para, por fora dos relatórios institucionais, 
compor aquilo que os poderes centrais preferiam não ver. A obra de Guimarães Rosa ajuda a pensar a própria modernização do Brasil, vista de dentro, de fora e de cima.

O diálogo entre Arte e Ciência, quando contextualizado, permite investigar o pensamento histórico sobre o território que configura esse país, bem como as suas dinâmicas. Pensar em quem escreveu sobre o Brasil, incluindo os não cientistas, mas também afeitos ao movimento territorial, ajuda a traçar a nossa história do pensamento geográfico para além da própria Geografia ${ }^{19}$.

\section{CONSIDERAÇÕES FINAIS}

Para as ciências humanas, ler a obra de Guimarães Rosa ainda se faz necessário, buscando nas entrelinhas a contradição que o autor apresenta sobre o sertão enquanto território forjado pelas contradições do capital e, ao mesmo tempo, de resistência à violência da sociabilidade moderna. Para a Geografia, o debate permite ir além do bioma cerrado, pois o autor registra momentos da vida e suas complexas e modernas relações sociais num período em que os documentos institucionais camuflam tais tratos. Também se permite entender o modo de ser nesse território a partir da imposição da sociabilidade moderna, vislumbrando criticar um viés fenomenológico alheio à constituição moderna do sertão e toda a bagagem alienante na produção desse espaço. Cabe à literatura ficcional marcar esses liames, pois provida de maior liberdade, não deixaria de ser também um documento de denúncia e reflexão.

Que mais investigações como esta, quais sejam sobre o sujeito e suas intenções, ainda venham à luz, pois contribuiriam no debate sobre como os intelectuais, não ingenuamente envolvidos na formação da literatura brasileira e suas representações do país, pensavam o território nacional. Ao abordar o sertão como uma alegoria do Brasil e também do mundo moderno, aposta-se que Guimarães Rosa foi um dos pensadores clássicos da formação brasileira, pois apresentou o sertão na sua contradição em processo: a pobreza econômica e a submissão dos capiaus aos jagunços e coronéis como parte do processo de territorialização econômica, mas também os traços sensíveis entre aqueles que, a despeito do sofrimento, encontram beleza na particularidade desse espaço, onde estão amalgamados natureza e sociedade, violência e anticlímax, o Bem e o Mal. À

\footnotetext{
${ }^{19}$ Para Antonio Candido, a literatura ficcional brasileira foi gestada para ocupar um vazio que as ciências ainda não tinham condições de preencher, sendo produzidas por literatos preocupados com a ideia nacional (CANDIDO, 2006).
} 
Geografia, a Literatura faz um convite a olhar para um sertão que "está movimentante a todo-tempo" (ROSA, 1986, p. 456) de forma não dualista, nem ingenuamente deslumbrado, pois forjado nas relações capitalistas, ele apresenta ao mesmo tempo o negativo e o positivo como parte de um mundo muito misturado.

Por fim, acredita-se que a literatura roseana endossa a proposição de que o sertão não é apenas ideologia geográfica, mas é território. Ao sê-lo, possui historicidade, e é dela que exala a inspiração para criar os personagens e seus contextos. Por ser território, relações de poder e interesses também estão postos, cabendo questionar que tipo de poder está em jogo, bem como o contexto em que ocorreu - os conflitos envolvendo coronéis, jagunços e capiaus, além do papel das mulheres, que atravessam boa parte das tramas dão pistas do jogo de forças e dos atores envolvidos. Enquanto ideologia geográfica, os contos referentes à construção da cidade e toda a metáfora de migração para os centros urbanos revelam o sertão imaginado pelas camadas dominantes que negam a história e a vivência dos muitos sertanejos, cujos projetos só podem ser traçados porque existe um território concreto que alimenta o discurso ideológico. É nesse território, onde se impôs uma nova relação de produção e de troca, que também se buscou por formas de solidariedade que possibilitaram enxergar a beleza, apesar da violência do valor. Portanto, o sertão roseano só pode ser compreendido como percepção e imaginário preso à forma categorial moderna, a qual exige novas sociabilidades a partir da apropriação daqueles vastos espaços, onde os laços de solidariedade se dão como luta pela sobrevivência impondo limites à consciência e influenciando o conteúdo sensível de seus sujeitos - o que requer evitar um viés fenomenológico e individualista que ignora o conteúdo e o contexto histórico em que ele foi forjado. O sertão não é um vazio. Ele é moderno, e no moderno reside a dor e a beleza da contradição.

\section{REFERÊNCIAS}

ADORNO, Theodor; HORKHEIMER, Max. Dialética do esclarecimento: fragmentos filosóficos. Tradução de Guido Antonio de Almeida. Rio de Janeiro: Jorge Zahar Editor, 1985.

AMADO, Janaina. Região, sertão, nação. Estudos Históricos, Rio de Janeiro, v. 8, n. 15, p. $145-15,1995$.

AUERBACH, Erich. Mimesis. São Paulo: Perspectiva, 2007. 
BIZZARRI, Edoardo. João Guimarães Rosa: correspondência com seu tradutor italiano Edoardo Bizzarri. Rio de Janeiro: Nova Fronteira, 2003.

BOLLE, Willi. Grandesertao.br: o romance de formação do Brasil. São Paulo: Duas Cidades; Editora 34, 2004.

CANDIDO, Antonio. Jagunços mineiros de Cláudio a Guimarães Rosa. In: CANDIDO, Antonio. Vários escritos. São Paulo: Duas Cidades, 1970.

CANDIDO, Antonio. Literatura e sociedade. Rio de Janeiro: Ouro Sobre Azul, 2006.

CUNHA, Euclides da. Os sertões: campanha de Canudos. Rio de Janeiro; São Paulo: Laemmert \& C. Editores, 1905.

FRANCO, Maria Sylvia de Carvalho. Homens livres na ordem escravocrata. São Paulo: Unesp, 1997.

GALVÃO, Walnice Nogueira. As formas do falso: um estudo sobre a ambiguidade no Grande Sertão: Veredas. 2 ed. São Paulo: Editora Perspectiva, 1986. (Coleção Debates). GALVÃO, Walnice Nogueira. O mesmo e o outro no sertão. Revista Imaginário: diversidade cultural. São Paulo, n. 9, 2003.

IBGE. Introdução. Atlas das representações literárias das regiões brasileiras. Rio de Janeiro: IBGE, v. 2, 2009a.

IBGE. Sertões do ouro e Sertões dos Currais. Atlas das representações literárias das regiões brasileiras. Rio de Janeiro: IBGE, v. 2, 2009 b.

KURZ, Robert. $O$ colapso da modernização: da derrocada do socialismo de caserna à crise da economia mundial. Tradução de Karen Elsabe Barbosa. Rio de Janeiro: Paz e Terra, 1992.

KURZ, Robert. Ontologia negativa: os obscurantistas do Esclarecimento e a moderna metafísica da história. In: KURZ, Robert. Razão sangrenta: ensaios sobre a crítica emancipatória da modernidade capitalista e de seus valores ocidentais. São Paulo: Hedra, 2010 .

LAMBERT, Jacques. Os dois Brasis. São Paulo: Companhia Editora Nacional, 1972.

LEFEBVRE, Henri. A produção do espaço. Tradução do grupo As (im)possibilidades do urbano na metrópole contemporânea. [S. l.]: Núcleo de Geografia Urbana da UFMG, 2006.

LE GOFF, Jacques. O deserto-floresta no Ocidente medieval. $O$ imaginário medieval. São Paulo: Estampa, 1994. (Série Nova História)

MARX, Karl. O Capital: crítica da economia política. São Paulo: Boitempo Editorial, 
2013. 3 v.

MELO, Adriana Ferreira de. O lugar-sertão: grafias e rasuras. Orientador: Cássio Eduardo Viana Hissa. 2006. Dissertação (Mestrado em Geografia Humana) - Instituto de Geociências, Universidade Federal de Minas Gerais, Belo Horizonte, 2006.

MORAES, Antonio Carlos Robert. "Sertão: um „outro“ geográfico”. Terra Brasilis Território, anos III-IV, n. 4-5. Rio de Janeiro, 2002, 11-23.

MOREIRA, Eidorfe. Sertão - a palavra e a imagem. Boletim Geográfico, Belém, ano 5, n. 52 , p. $403,1959$.

MORETTI, Franco. Atlas do romance europeu (1800-1900). Tradução de Sandra Guardini Vasconcelos. São Paulo: Boitempo, 2003.

NASH, Roderick Frazier. Wilderness and the american mind. [S. l.]: Yale University Press, 2001.

OLIVEIRA, Francisco de. Elegia para uma re(li)gião: Sudene, Nordeste. Planejamentos e conflitos de classes. Rio de Janeiro: Paz e Terra, 1977.

PACHECO, Ana Paula. Lugar do mito: narrativa e processo social nas Primeiras estórias de Guimarães Rosa. São Paulo: Nankin, 2006.

PALMÉRIO, Mário. Vila dos Confins. Rio de Janeiro: José Olympio Editora, 1976.

PASTA JR., José Antônio. O romance de Rosa. Temas do grande sertão e do Brasil. In: QUINT, Anne-Marie (Org.). La Ville: exaltation et distanciation. Études de literature portugaise et brésilienne. Paris: Presses de la Sorbonne Nouvelle, 1997.

PRADO JR. Caio. Formação do Brasil contemporâneo. São Paulo: Brasiliense, 2006.

RIBEIRO, Darcy. O Brasil sertanejo. In: RIBEIRO, Darcy. O povo brasileiro: a formação e o sentido do Brasil. São Paulo: Cia. das Letras, 1995

RONCARI, Luiz. Dez teses para o estudo de João Guimarães Rosa. Scripta, [s. l.], v. 5, n. 10, PUC Minas, $1^{\circ}$ semestre/2002.

RONCARI, Luiz. O Brasil de Rosa: o amor e o poder. São Paulo: Unesp, 2004

ROSA, João Guimarães. Grande sertão: veredas. Rio de Janeiro: Nova Fronteira, 1986.

ROSA, João Guimarães. Primeiras estórias. Rio de Janeiro: Nova Fronteira, 2006a.

ROSA, João Guimarães. Sagarana. Rio de Janeiro: Nova Fronteira, 2006b.

SADER, Maria Regina; PAULINO, Ana Maria. A ordem e a desordem no sertão. Revista do IEB, São Paulo, n. 41, 1996.

SAMPAIO, Teodoro. O rio de São Francisco e a Chapada Diamantina. São Paulo: Escolas Profissionais Salesianas, 1905. 
SANTOS, Milton. A natureza do espaço: técnica e tempo, razão e emoção. São Paulo: Edusp, 2000.

SCHOLZ, Roswitha. A nova crítica social e o problema das diferenças: disparidades económicas, racismo e individualização pós-moderna. O Beco, 2004. Disponível em: http://www.obeco-online.org/roswitha_scholz3.htm. Acesso em: 20 mar. 2017.

SPERBER, Suzi Frankl. Amor, medo e salvação: aproximações entre Valdomiro e Guimarães Rosa. Revista do IEB, São Paulo, n. 41, 1996.

STARLING, Heloísa. Lembranças do Brasil: teoria, política, história e ficção em “Grande Sertão: Veredas”. Rio de Janeiro: Revan, 1998.

WISNIK, José Miguel. Recado da viagem. Scripta, [s. l.], v. 2, n. 3, 1998.

Recebido em 05/03/2020.

Aceito em 14/09/2020.

Publicado em 07/11/2020. 